\title{
Evaluating the Landslides Characterization and Deformation Using Multi-Temporal Uav Imageries in Northern Pakistan
}

Muhammad Shafique ( $\sim$ shafique08@yahoo.com )

National Centre of Excellence in Geology, University of Peshawar https://orcid.org/0000-0002-40636666

Naseem Ahmad

University of Peshwar

Mian Luqman Hussain

University of Peshawar

\section{Research Article}

Keywords: Un-Manned Aerial Vehicle (UAV), Surface Movement, Point cloud, Orthomosaic, DSM, Landslide

Posted Date: May 17th, 2021

DOI: https://doi.org/10.21203/rs.3.rs-475414/v1

License: (c) (1) This work is licensed under a Creative Commons Attribution 4.0 International License. Read Full License 


\section{Abstract}

The Un Manned Aerial Vehicles (UAVs) have emerged as an effective tool for mapping and evaluating the landslides dynamics. This study aims to evaluate the dynamics of the landslide using the UAV derived aerial photos and Digital Surface Model (DSM). The selected landslides are the Nara and Nokot landslides in the rough terrain of Balakot, north Pakistan. The UAV survey was carried in April and August 2019 for Nara and Nokot landslides in Balakot. The images were processed in the Pix4D mapper to compute the orthomosaic and DSMs. The Ground Control Points (GCPs) collected in the geodetic survey with the Global Navigation Satellite System (GNSS) using Post Processing Kinematic (PPK) were used to accurately co-register and orthorectify the UAV imageries. The derived DSMs were analyzed to evaluate the dynamics in the landslide's topography and volumetric changes. The shaded relief single band was used to correlate the temporal images for the Nara and Nokot landslide using the COSI-Corr algorithm. The statistical and frequent correlator was used for landslide displacement. The result shows that the Nara landside has a surface movement ranging from 1 to $29 \mathrm{~m}$ in the NE scarp and lateral areas. The Nokot landslide has active NS, NE and NW scarps with a surface movement ranging from 1 to $25.5 \mathrm{~m}$. The accuracy assessment reveals the RMSE calculated for the Nara landslide as $4.58 \mathrm{~m}$ and $4.24 \mathrm{~m}$ for the Nokot landslide. This study reflected the potential application of UAVs for monitoring the landslides dynamics to mitigate the hazard.

\section{Introduction}

Landslides are among the most destructive geological hazards in mountainous regions. Over the global scale, landslides have caused significant economic losses and human fatalities in mountainous terrains (Solaimani et al. 2013). The topographic features, geology, geomorphology, landuse and land cover have a significant impact on the spatial distribution and intensity of landslides (Eker et al. 2017). The triggering factors for the landslides can be exclusively natural e.g. tectonic activities, precipitation and ground freeze/thaw successions or anthropogenic e.g. excavation or deforestation (Ali et al. 2017; Asghar 2017). To mitigate the consequences of landslides, detailed characterization and monitoring of the landslides are critical to understanding the triggering mechanisms (Martins et al. 2020).

For regional-scale landslide characterizations and monitoring, a range of spaceborne remote sensing platforms has been widely and effectively applied (Gorum et al. 2011; Parkash 2013; Gnyawali et al. 2019; Bradley et al. 2019). However, the data acquired from the space-borne remote sensing platforms have the limitation of coarse spatial and extended temporal resolution; and dependency on the weather conditions (Casagli et al. 2017; Hu et al. 2012). High-resolution imageries like the Pleiades help produce good results but the high economic values restrict the use of Pleiades imageries (Clapuyt et al. 2017). This has so far limited the use of high-resolution satellite imageries for mapping and monitoring the landslide deformation (Niethammer et al. 2009). In contrast to spaceborne and airborne remote sensing, the Un Manned Aerial Vehicles (UAVs) have expanding and resourceful applications (Pillon et al. 2020). For landslide mapping and research, the UAVs are repeatedly and effectively used as remote sensing platform (Zeybek and Şanlıoğlu 2020) The UAVs can be used standalone or aided with the large scale 
characterization and monitoring of landslides can be effectively achieved through the very fine resolution aerial photos (Eker et al. 2017). Large scale characterization and monitoring of landslides can be effectively achieved through very fine resolution aerial photos (Martins et al. 2020).

Recently, the UAVs based aerial survey and derived very fine resolution orthophotos and elevation data are repeatedly and effectively applied for large scale landslide monitoring and characterization (Casagli et al. 2017; Shi and Liu 2015; Lindner et al. 2016; Peternel et al. 2017). The major capabilities of UAV data are its high spatial resolution, accurate, fly on-demand for near real-time, and carrying multiple sensors with flexibility and safety of operations, quick disposition, robustness, cost-effectiveness, and capability to work in bad weather conditions like clouds, give the UAVs a lead over the traditional aerial and spaceborne platforms (Asghar 2017; Shahbazi et al. 2015; Lindner et al. 2016).

Mountainous terrains in Pakistan are subject to frequent landsliding given the rugged topography, active tectonic, monsoonal climate and anthropogenic activities on the fragile slopes. (Kumar and Bhagavanulu 2008). A range of studies has utilized the space-borne remote sensing data for landslide assessments and monitoring (Shafique 2020; Khan et al. 2018; Bacha et al. 2018; Shafique et al. 2016). However, detailed characterization and monitoring of the high-risk landslides using UAVs data, is lacking for the area to assist in understanding its dynamics and triggering mechanism (Asghar 2017). This study aims to utilize the UAVs derived orthophotos and topographic information for landslide characterizations and displacement in the landslide-prone area of Balakot. Moreover, the study provides a detailed insight into the use of SfM algorithm aided with the Differential Global Positioning System (DGPS) for generating high-resolution orthomosaic and DSMs.

\subsection{Study area}

The Nara and Nokot landslides are situated in Balakot valley in the district of Mansehra, Pakistan (Fig. 1). The average elevation of the Nara and Nokot landslides ranges from 905 to $1320 \mathrm{~m}$ above mean sea level. The valley has a mean maximum temperature of $15.9^{\circ} \mathrm{C}$ in winter and $37.6^{\circ} \mathrm{C}$ in summer, while the mean minimum temperature is $3.2^{\circ} \mathrm{C}$ in winters and $22.1^{\circ} \mathrm{C}$ in summer with annual $1588 \mathrm{~mm}$ precipitation (Rahman et al. 2018). The lithology of the area is dominated by sedimentary rocks e.g. shale, limestone and fractured sandstone (Basharat et al. 2016; Calkins et al. 1975).

\section{Material And Methods}

\subsection{Image acquisition and pre processing}

A remotely controlled quadcopter i.e. DJI Inspire 2 (Fig. 2A) was used for mapping the Nara and Nokot landslides. Quadcopter Inspire has a take-off weight of $1.28 \mathrm{~kg}$ (camera and battery included for increased stability in the air) with a Xemuse $X 4$ gimbal having a $120^{\circ}$ tilt range (Asghar 2017). The gimbal holds the UAV's camera and harmonizes with the movement of the UAVs for image acquisition. Besides this, the Inspire 2 is mounted with ordinary GPS/GLONASS (Thomas et al. 2019) which is used 
for the accurate positioning of grid path and takeoff and landing (Asghar 2017). The Visual Positioning System (VPS) attached below the UAVs, consists of ultrasonic sensors and a monocular camera which enhances the $X Y Z$ accuracies up to $=/-0.1-0.5 \mathrm{~m}$ (Asghar 2017). For accurate orthorectification, $a$ geodetic survey was carried out using a Differential Global Positioning System (DGPS) in Post Processing Kinematics (PPK) was used (Fig. 2B). The wooden tiles of $18 \times 18$ Inches (Fig. 2D) with black and white painting and the centroid visible in black were used as Ground Control Points (GCPs) The DGPS provides the accuracy of $1-1.5 \mathrm{~cm}$ in field geodetic survey (Asghar 2017). For the UAV survey, the double grid mission (waypoint mode) was used in the Pix4D capture application (Fig. 2C). The frontal and side overlap of $85 \%$ is recommended and used for SfM based mapping techniques (Lucieer et al. 2013; Turner et al. 2014; Turner et al. 2012). The ISO was fixed at 100 for noise reduction (Mateos et al. 2017). The UAV was set to the duration of 2 seconds to capture all images with a speed of $4.6 \mathrm{~m}$ per hour. The image was processed in the structure algorithm called "Pix4D Mapper" resulting in highresolution DSM and orthomosaic of $8 \mathrm{~cm}$ from multiple snaps (Table 1) accurately ortho-rectified using the acquired GCPs. The pre and post DSMs and orthomosaics generated were resampled to the same resolution to accurately map the surface displacement. The accuracy assessment of the DSMs and GCPs collected in the field were validated using RMSE.

Table 1

Details of a temporal aerial survey carried out for the Nara and the Nokot landslide

\begin{tabular}{|lllllll|}
\hline S.No & LS & Date & Snaps & Spatial Res & Temporal Res & Weather Condition \\
\hline 1 & Nara & $04-04-19$ & 173 & $8 \mathrm{~cm}$ & - & Sunny, Light Wind \\
\hline 2 & Nara & $15-08-19$ & 169 & $7 \mathrm{~cm}$ & 170 days & Sunny, Light Wind \\
\hline 3 & Nokot & $04-04-19$ & 201 & $7 \mathrm{~cm}$ & -- & Sunny, Light Wind \\
\hline 4 & Nokot & $15-08-19$ & 197 & $8 \mathrm{~cm}$ & 170 Day & Sunny, Light Wind \\
\hline
\end{tabular}

\subsection{Data analysis}

\subsubsection{DSM changes, volume and volume loss calculation}

To evaluate the topographic variation, the pre DSMs of the Nara and the Nokot landslides generated were subtracted from the post DSMs. The DSM changes were then multiplied by the resolution of the DSM to acquire the volume. The area of the volume was calculated using the total pixel count in the landslide boundary. Once the DSM changes are made, the volume loss of the landslide was also calculated using total pixel count and area. The bulking factor was calculated using a raster calculator by dividing the post DSMs by Pre DSMs. The bulking factor was used to estimate the excavation in the landslide.

\subsubsection{Transect through the slope}

A profile was drawn along the slope (Fig. 6 and Fig. 8) surfaces and points were generated along the line. A $2.5 \mathrm{~m}$ buffer was created around the points. The zonal statistics analysis was carried out to extract the means of changes in the slope values within the buffer zone. 


\subsubsection{Tracking surface movement using COSI Corr}

After the precise processing of UAV imageries, the COSI Corr analysis was carried out using the statistical correlator and frequential correlator (Turner et al. 2012). The frequential correlator is a Fourier based and is more precise than the statistical one (Haque 2016; Leprince 2008). The statistical correlator is coarser, however, robust than the frequential correlator as it maximizes the absolute value of the correlation coefficient (Lucieer et al. 2013). It can be used for coarse imageries like aerial photographs and UAVs imageries (Turner et al. 2014). The hillshade images were analyzed with both the correlator. The correlator resulted in three outputs i.e. North/South displacement, East/West Displacement and SNR (Sound Noise Ratio). However, it was found that the frequential correlator does not work on the UAV imageries as the COSI Corr is sensitive to noise containing images (Turner et al. 2014; Asghar 2017). Therefore, the statistical correlator was used for detecting surface displacement with a window size of 64, step size 8 and a search radius of 50 pixels (Lucieer et al. 2013). The NS and EW displacement and SNR resulted in the vectors representing the directional displacement.

\section{Results And Discussion \\ 3.1 Results}

\subsubsection{DSM changes, volume and volume loss calculation}

The DSMs acquired in April and August 2019, were analyzed to evaluate the topographic changes of the Nara landslide (figure 4). The Nara landslide has a loss of volume ranging from -11.28 to -1 to $3 \mathrm{~m}$ at the leading edge of the toe. The eroded material is deposited at the lower part of the toe with a gain of 1 to $16.38 \mathrm{~m}$. There are patches of volume changes in the scarp (figure 4a) of the Nara landslide. However, largely, the scarps collapse and the toe advances with the gain in the volume. The lower leading edge (figure $4 \mathrm{~b}$ ) above the toe (figure $4 \mathrm{c}$ ) has been excavated anthropogenically with a volume loss of -11.28 $\mathrm{m}^{3}$ and the toe has gained $11.6 \mathrm{~m}^{3}$ of volume. The bulking factor of any landslide has a fixed threshold of 2 i.e. the values vary between 0 and 2 for such type of landslide (Turner et al., 2014). The total volume of the Nara landslide calculated is $297538.92 \mathrm{~m}^{-3}$ with a volume loss of $1299.84 \mathrm{~m}^{-3}$ (Table 2). The bulking factor for the Nara landslide (table 2) is 1.007.

The Nokot landslide is spread on two sides making it a valley-shaped landslide. The Nokot landslide (figure $5 b$ ) has its scarp extended on both northwestern (figure 5a) and northeastern (figure 5b) directions. The scarp is collapsed in the north-eastern (figure $5 \mathrm{~b}$ ) direction. The volume is lost and is gained below the scarp lateral part ranging from -14 to $-1 \mathrm{~m}$ with a gain ranging from 1 to $8.10 \mathrm{~m}$. The NW scarp has some vegetation stabilizing the landslide. However, the scarp has retreated. The centralnorthern (figure $5 \mathrm{c}$ ) scarp has a significant volume loss directed towards the western side ranging from -14 to $-1 \mathrm{~m}$. This volume loss is the result of human-induced excavation (Figure 12b). The total volume of 
the Nara landslide calculated is $639023.54 \mathrm{~m}^{-3}$ with a volume loss of $3312.08 \mathrm{~m}^{-3}$ (Table 2). The Bulking Factor (Table 2) calculated for the Nokot landslide is 0.98.

Table 2: shows the area, volume, volume loss and bulking factor of the Nara and the Nokot landslide

\begin{tabular}{|llllll|}
\hline S. No. & LS & Area $\mathrm{m}^{2}$ & Total Volume $\mathrm{m}^{-3}$ & Volume Loss $\mathrm{m}^{-3}$ & Bulking Factor \\
\hline 1. & Nara Landslide & 77861.794 & 297538.92 & 1299.84 & 1.007 \\
\hline 2. & Nokot Landslide & 58123.432 & 639023.54 & 3312.08 & 0.98 \\
\hline
\end{tabular}

\subsubsection{Transect through topographic changes}

The Nara landslide (figure 6 and 7) has been excavated (encircled in white) with a volume loss of $-14.8 \mathrm{~m}$. This excavation has made the particular zone a highly dynamic area (figure $7 \mathrm{~b}$ ) of the Nara landslide. The graph has sunk above the toe (figure 7c) encircled with green color. It can be observed that there are no other significant changes in the transect line through the slope. The scarp portion (figure 7a) is stable with a movement in the material but there are very few changes of slope less than 1 degree. There is no collapse in the NW secondary scarp and toe (figure 7b) even though it is also upright faced and covered with loose debris. The leading toe (figure 7c) has only been excavated and reduced the slope up to 15 degrees. Based on these dynamics, the lateral leading toe (figure 7c) portion may surge again shortly.

In the Nokot landslide (figure 9 and 10), there is a surge in the NS scarp (figure 8a) encircled with white ranging from 3 to 4 degrees. These changes in the slope indicate that there is a possibility of the NS scarp (figure 9a) will surge in near future. The lower portion i.e. the valley floor and the toe (figure 9b) of the landslide resembles small changes. These variations represent the changing scenario of slope in the valley floor of the Nokot landslide. There has been a noticeable change of 4-5 degrees in the lower region (b) of the landslide.

\subsubsection{Surface movement}

For the Nara landslide, the COSI Corr result (figure 10) shows that the NE main scarp (figure 10a) has retreated with a movement of 20 to $25 \mathrm{~m}$. The scarp has surged in the NS direction towards the toe. The NE scarp has also surged from the left side directed and the movement is directed towards the east with a rate of 18 to $26.5 \mathrm{~m}$. The lower portion (figure $10 \mathrm{~b}$ ) of the main body of the landslide i.e. the main track above the depositional area shows a significant movement headed towards the toe with a range of 25 to $29.5 \mathrm{~m}$ displacement. This particular area is the most excavated zone of the Nara landslide. The movement is directed towards the depositional area. The lower right NE (figure 10d) area above the depositional area has displaced from 17.5 to $23 \mathrm{~m}$ with a direction towards the depositional area. The zone of depletion (figure 10b) has a displacement of 8.5 to 17.5 toe directed. The remaining portion of the landslide has no displacement, however, there are some patches in the mid with a displacement of 17 to $19 \mathrm{~m}$. The lower toe portion (figure 10c) shows a very low change ranging from 0-4.45 m. The area 
above the northwestern toe (figure 10e)also shows significant stablility and the a very less movement ranging from 0 to $4.45 \mathrm{~m}$ is observed. In the secondary scarp (figure 10f), it is relatively stable with no movement in the scarp and depletion area. However, a significant displacement in patches at the toe ranging from 15 to $29 \mathrm{~m}$ has been observed.

The Nokot landslide (figure 11) NE scarp (figure 11a) has high values of surface displacement ranging from 8 to $15 \mathrm{~m}$ is recorded and this scenario is stretched along the scarp from the start point till the toe. As discussed earlier, the landslide is valley shaped and the surged scarps deposit the loose material on the valley floor which is then removed by rainfall and anthropogenic factors. The NS central scarp (figure $11 \mathrm{~b}$ ) is the most active part of the Nokot landslide with a surface movement ranging from 7 to $18 \mathrm{~m}$. This particular portion of the landslide is faced both towards east and west and both scarps are surging and depositing the debris on the valley floor. The frontal valley faced scarp has also surged with a rate of 18 to $22 \mathrm{~m}$. The NW scarp (figure 11c) opposite to NS scarp (b) has surged with a displacement of 18 to $25.5 \mathrm{~m}$. However, a portion shown in figure $11 \mathrm{~d}$ is stabilizing due to vegetation with a movement of 0 to $1.5 \mathrm{~m}$. The lateral portion of the NW scarp near the toe is showing high values of movement ranging from 18 to $25.5 \mathrm{~m}$. The valley floor (figure 11e) is the depositional zone of this landslide where the debris is deposited and later on moved with rainfall and due to anthropogenic activities. The lower toe (figure 11g) area of the landslide also shows a movement ranging from 11 to $15 \mathrm{~m}$ due to the water channel (figure 11f) eroding in the rainfall season. The black arrows show the direction of the surface movement while the length of the arrows describes the amount of material displaced.

\subsection{Accuracy Assessment}

The Nara landslide has 4.58m of RMSE (Table 3) aided with 17 GCPs and the Nokot landslide has a total number of 13 GCPs plotted with RMSE of $4.24 \mathrm{~m}$ (Table 3). The $\mathrm{R}^{2}$ for the Nara landslide reported is $0.85 \%$ and that of the Nokot landslide is $0.86 \%$.

Table 3: shows the no of GCPs used and vertical RMSE of DSMs

\begin{tabular}{|lllll|}
\hline S.No & Landslide & No of GCPs & Coefficient of Correlation $\left(\mathbf{R}^{2}\right)$ & RMSE \\
\hline 1. & Nara Landslide & 17 & 0.85 & 4.58 \\
\hline 2. & Nokot Landslide & 13 & 0.86 & 4.24 \\
\hline
\end{tabular}

\subsection{Discussion}

This study demonstrates the UAV derived aerial photos and subsequent analysis as an effective tool for monitoring and understanding the landslides dynamics. The alignment of aerial photos with a high overlap rate reduces the error during pre-processing in the SfM algorithm (Turner et al., 2014). Therefore, an overlap of $85 \%$ leads to computing a high resolution orthomosaic and DSMs aided with the GCPs using a DGPS. Linder et al., (2016) used 70\% and 90\% overlap at the low slope area of Pechgraben 
landslide generating a dense point cloud. Asghar. (2017) used a 70\% to $90 \%$ overlap due to hilly terrain, however, Lucieer et al, (2013) used $80 \%$ to $90 \%$ overlap with low slope area of Home Hill landslide Tasmania resulting in dense point cloud generation. This study used $85 \%$ to $90 \%$ overlap due to hilly terrain and acquired a $7.7 \mathrm{~m}^{3}$ of point cloud density. Lucieer et al., (2013) achieved a vertical RMSE of 6.2 for the Home Hill landslide. In this study, the RMSE for the DSMs and orthomosaic created is 4.24 and 4.58 for the Nara and the Nokot landslide using 17 and 13 GCPs respectively.

The volumetric changes can have an error due to the processing of DSMs, however, the volume changes in a large set of areas can reduce this inaccuracy to the small percentage of total volume. The high temporal resolution with regular dataset collection can increase the understanding of landslide and its pattern of movement. Asghar, (2017), Turner et al., (2014) and Lucieer et al., (2013) monitored the landslide with a temporal resolution of 1 year. Lindner et al., (2015) monitored the landslide with 1 to 2 months of temporal resolution. This study has a temporal resolution of 4 months, however, lacks the historical data in form of aerial photographs and high-resolution satellite imageries. With the UAV, 14 days of optimal temporal resolution can help monitor the landslide movement in more detail.

The correlation method selection in COSI Corr is dependent on the type, source and spatial resolution of data. The windows size for the statistical correlator can be changed to give different results but the windows size 64 with a step size 8 and a search radius of 50 gives the better results for UAV-based correlation (Turner et al., 2014). Turner et al., (2014) used COSI Corr for landslide displacement study and found that the UAV based derivatives cannot be processed on every window and step size of COSI Corr. A windows size lower than 32 leads to noisy results. Step size 4 does not work on UAV derivatives. The COSI Corr helped to detect the meter level displacement in the Nara and the Nokot landslides. The windows size 128 works on the UAV derivatives and are used by Lucieer et al., (2013) but the window size 64 gave the meter level of displacement in the Nara and the Nokot landslide.

Human-induced excavation (Figure 12) in the Nara (Figure 12a) and the Nokot landslide (Figure 12b) is playing a vital role in the destabilization of the landslides beside that the region is seismically active.

However, during the mapping of these landslides, the rough topography was a challenge. The elevated moutntain covered with dense forest were difficult to be mapping and created obstacles for aerial surveys leading to loss of connection between the UAV and remote controller.

\section{Conclusion}

It is determined that the Nara and Nokot landslides have a significant displacement in the scarp and toe regions and it can lead to a serious disaster in near future. This study reaffirms that the UAVs based remote sensing approach has the potential to produce high-resolution orthomosaics and Digital Surface Models (DSMs). The SfM algorithm leads to accurate orthorectification with the assistance of Differential Global Positioning System (DGPS). Additionally, with the use of COSI Corr, monitoring the landslides surface movement has bridged the gap to study the landslide at a large scale. Furthermore, it also helped 
explore the micro-level deformation occurrence of landslides which helped in producing centimeter-level detailed mapping of the deformation. The Nara and the Nokot landslides have an overall displacement ranging from 0.5 to $29 \mathrm{~m}$. This subtle change is both induced naturally as well as due to anthropogenic activities over the landslides. The multi-temporal UAV based monitoring is a very useful and cost-effective technique for monitoring and understanding the landslides dynamics and accordingly mitigation.

\section{Declarations}

\section{Acknowledgment}

The funding for the study is provided by the Pakistan Science Foundation project number PSF/NSFC/Earth-KP-UoP(11)) and Natural Science Foundation China grant No.41661144028

Funding (The Funding for the project is provided by the Pakistan Science Foundation project number PSF/NSFC/Earth-KP-UoP(11)) and Natural Science Foundation China grant No.41661144028)

Conflicts of interest/Competing interests (There is no conflict of interests)

Availability of data and material (It is available)

Code availability (Not applicable)

\section{Authors' contributions}

(Naseem Ahmed: Implemented the study and written the manuscript

Muhammad Shafique: Designed the study and assisted in the manuscript structure and text

Mian Luqman Hussain: Assist in the field in UAV flights and data analysis)

\section{References}

Ali, M. Z., Ullah, S., \& Ali, A. (2017). Impact assessment of spatial resolution on landslide inventories: A case study of Muzaffarabad city. Journal of Himalayan Earth Sciences Volume, 50(2), 114-124.

Asghar, U. (2017). Landslide Mapping From Analysis Of UAV-SfM Point Clouds The University Of British Columbia,

Bacha, A. S., Shafique, M., \& van der Werff, H. (2018). Landslide inventory and susceptibility modelling using geospatial tools, in Hunza-Nagar valley, northern Pakistan. [journal article]. Journal of Mountain Science, 15(6), 1354-1370, doi:10.1007/s11629-017-4697-0.

Basharat, M., Shah, H. R., \& Hameed, N. (2016). Landslide susceptibility mapping using GIS and weighted overlay method: a case study from NW Himalayas, Pakistan. [journal article]. Arabian Journal of 
Geosciences, 9(4), 292, doi:10.1007/s12517-016-2308-y.

Bradley, K., Mallick, R., Andikagumi, H., Hubbard, J., Meilianda, E., Switzer, A., et al. (2019). Earthquaketriggered 2018 Palu Valley landslides enabled by wet rice cultivation. Nature Geoscience, 12(11), 935-939, doi:10.1038/s41561-019-0444-1.

Calkins, J., Offield, T., Abdullah, S., \& Ali, S. T. (1975). Geology of the southern Himalaya in Hazara, Pakistan, and adjacent areas. US Govt. Print. Off, 2330-7102.

Casagli, N., Frodella, W., Morelli, S., Tofani, V., Ciampalini, A., Intrieri, E., et al. (2017). Spaceborne, UAV and ground-based remote sensing techniques for landslide mapping, monitoring and early warning. [journal article]. Geoenvironmental Disasters, 4(250-282), 9, doi:10.1186/s40677-017-0073-1.

Clapuyt, F., Vanacker, V., Schlunegger, F., \& Oost, K. V. (2017). Unravelling earth flow dynamics with 3-D time series derived from UAV-SfM models. Earth Surface Dynamics, 5(791), 791-806.

Eker, R., Aydın, A., \& Hübl, J. (2017). Unmanned aerial vehicle (UAV)-based monitoring of a landslide: Gallenzerkogel landslide (Ybbs-Lower Austria) case study. [journal article]. Environmental Monitoring and Assessment, 190(1), 28, doi:10.1007/s10661-017-6402-8.

Gnyawali, K. R., Zhang, Y., Wang, G., Miao, L., Pradhan, A. M. S., Adhikari, B. R., et al. (2019). Mapping the susceptibility of rainfall and earthquake triggered landslides along China-Nepal highways. [journal article]. Bulletin of Engineering Geology and the Environment, doi:10.1007/s10064-019-01583-2.

Gorum, T., Fan, X., van Westen, C. J., Huang, R. Q., Xu, Q., Tang, C., et al. (2011). Distribution pattern of earthquake-induced landslides triggered by the 12 May 2008 Wenchuan earthquake. Geomorphology, 133(3), 152-167, doi:https://doi.org/10.1016/j.geomorph.2010.12.030.

Haque, D. M. E. (2016). 3-D Surface Deformation Model from Sub-Pixel correlation of Optical Imagery and InSAR. University of Twente,

Hu, J. P., Wu, W. B., \& Tan, Q. L. (2012). Application of Unmanned Aerial Vehicle Remote Sensing for Geological Disaster Reconnaissance along Transportation Lines: A Case Study. Applied Mechanics and Materials, 226-228, 2376-2379, doi:10.4028/www.scientific.net/AMM.226-228.2376.

Khan, H., Shafique, M., Khan, M. A., Bacha, M. A., Shah, S. U., \& Calligaris, C. (2018). Landslide susceptibility assessment using Frequency Ratio, a case study of northern Pakistan. The Egyptian Journal of Remote Sensing and Space Science, 22(1), 11-24, doi:https://doi.org/10.1016/j.ejrs.2018.03.004.

Kumar, S. V., \& Bhagavanulu, D. (2008). Effect of deforestation on landslides in Nilgiris district-A case study. Journal of the Indian Society of Remote Sensing, 36(1), 105. 
Leprince, S. e. (2008). Monitoring Earth Surface Dynamics With Optical Imagery. California Institute of Technology Pasadena, California,

Lindner, G., Schraml, K., Mansberger, R., \& Hübl, J. (2016). UAV monitoring and documentation of a large landslide. [journal article]. Applied Geomatics, 8(1), 1-11, doi:10.1007/s12518-015-0165-0.

Lucieer, A., Jong, S. M. d., \& Turner, D. (2013). Mapping landslide displacements using Structure from Motion (SfM) and image correlation of multi-temporal UAV photography. Progress in Physical Geography, 38(1), 97-116.

Martins, B. H., Suzuki, M., Yastika, P. E., \& Shimizu, N. (2020). Ground Surface Deformation Detection in Complex Landslide Area-Bobonaro, Timor-Leste-Using SBAS DInSAR, UAV Photogrammetry, and Field Observations. Geosciences, 10(6), 245.

Mateos, R. M., Azañón, J. M., Roldán, F. J., Notti, D., Pérez-Peña, V., Galve, J. P., et al. (2017). The combined use of PSInSAR and UAV photogrammetry techniques for the analysis of the kinematics of a coastal landslide affecting an urban area (SE Spain). [journal article]. Landslides, 14(2), 743-754, doi:10.1007/s10346-016-0723-5.

Niethammer, U., Rothmund, S., Joswig, M., Malet, J. P., \& Bogaard, T. (2009). UAV-based remote sensing of the slow-moving landslide Super-Sauze.

Parkash, S. (2013). Earthquake Related Landslides in the Indian Himalaya: Experiences from the Past and Implications for the Future. In C. Margottini, P. Canuti, \& K. Sassa (Eds.), Landslide Science and Practice: Volume 5: Complex Environment (pp. 327-334). Berlin, Heidelberg: Springer Berlin Heidelberg.

Peternel, T., Kumelj, Š., Oštir, K., \& Komac, M. (2017). Monitoring the Potoška planina landslide (NW Slovenia) using UAV photogrammetry and tachymetric measurements. [journal article]. Landslides, 14(1), 395-406, doi:10.1007/s10346-016-0759-6.

Pillon, S., Martinucci, D., Bezzi, A., Casagrande, G., Fontolan, G., Bieker, F., et al. Monitoring of a landslide through the use of UAV survey. In EGU General Assembly Conference Abstracts, 2020 (pp. 7696)

Rahman, G., Atta ur, R., Samiullah, \& Dawood, M. (2018). Spatial and temporal variation of rainfall and drought in Khyber Pakhtunkhwa Province of Pakistan during 1971-2015. Arabian Journal of Geosciences, 11(3), 46, doi:10.1007/s12517-018-3396-7.

Shafique, M. (2020). Spatial and temporal evolution of co-seismic landslides after the 2005 Kashmir earthquake. Geomorphology, 362, 107228, doi:https://doi.org/10.1016/j.geomorph.2020.107228.

Shafique, M., van der Meijde, M., \& Khan, M. A. (2016). A review of the 2005 Kashmir earthquake-induced landslides; from a remote sensing prospective. Journal of Asian Earth Sciences, 118, 68-80, doi:http://dx.doi.org/10.1016/j.jseaes.2016.01.002. 
Shahbazi, M., Sohn, G., Théau, J., \& Menard, P. (2015). Development and Evaluation of a UAVPhotogrammetry System for Precise 3D Environmental Modeling. Sensors, 15(11), 27493-27524.

Shi, B., \& Liu, C. UAV for landslide mapping and deformation analysis. In International Conference on Intelligent Earth Observing and Applications, 2015 (Vol. 9808, pp. 12-29): SPIE

Solaimani, K., Mousavi, S. Z., \& Kavian, A. (2013). Landslide susceptibility mapping based on frequency ratio and logistic regression models. [journal article]. Arabian Journal of Geosciences, 6(7), 2557-2569, doi:10.1007/s12517-012-0526-5.

Thomas, O., Stallings, C., \& Wilkinson, B. (2019). Unmanned aerial vehicles can accurately, reliably, and economically compete with terrestrial mapping methods. Journal of Unmanned Vehicle Systems, 8(1), 5774.

Turner, D., Lucieer, A., \& Jong, S. M. d. (2014). Time Series Analysis of Landslide Dynamics Using an Unmanned Aerial Vehicle (UAV). Remote Sensing, 7, 1736-1757.

Turner, D., Lucieer, A., \& Watson, C. (2012). An Automated Technique for Generating Georectified Mosaics from Ultra-High Resolution Unmanned Aerial Vehicle (UAV) Imagery, Based on Structure from Motion (SfM) Point Clouds. Remote Sensing, 4(5), 1392-1410.

Zeybek, M., \& Şanlıoğlu, İ. (2020). Investigation of landslide detection using radial basis functions: a case study of the Taşkent landslide, Turkey. Environmental Monitoring and Assessment, 192(4), 230, doi:10.1007/s10661-020-8101-0.

\section{Figures}



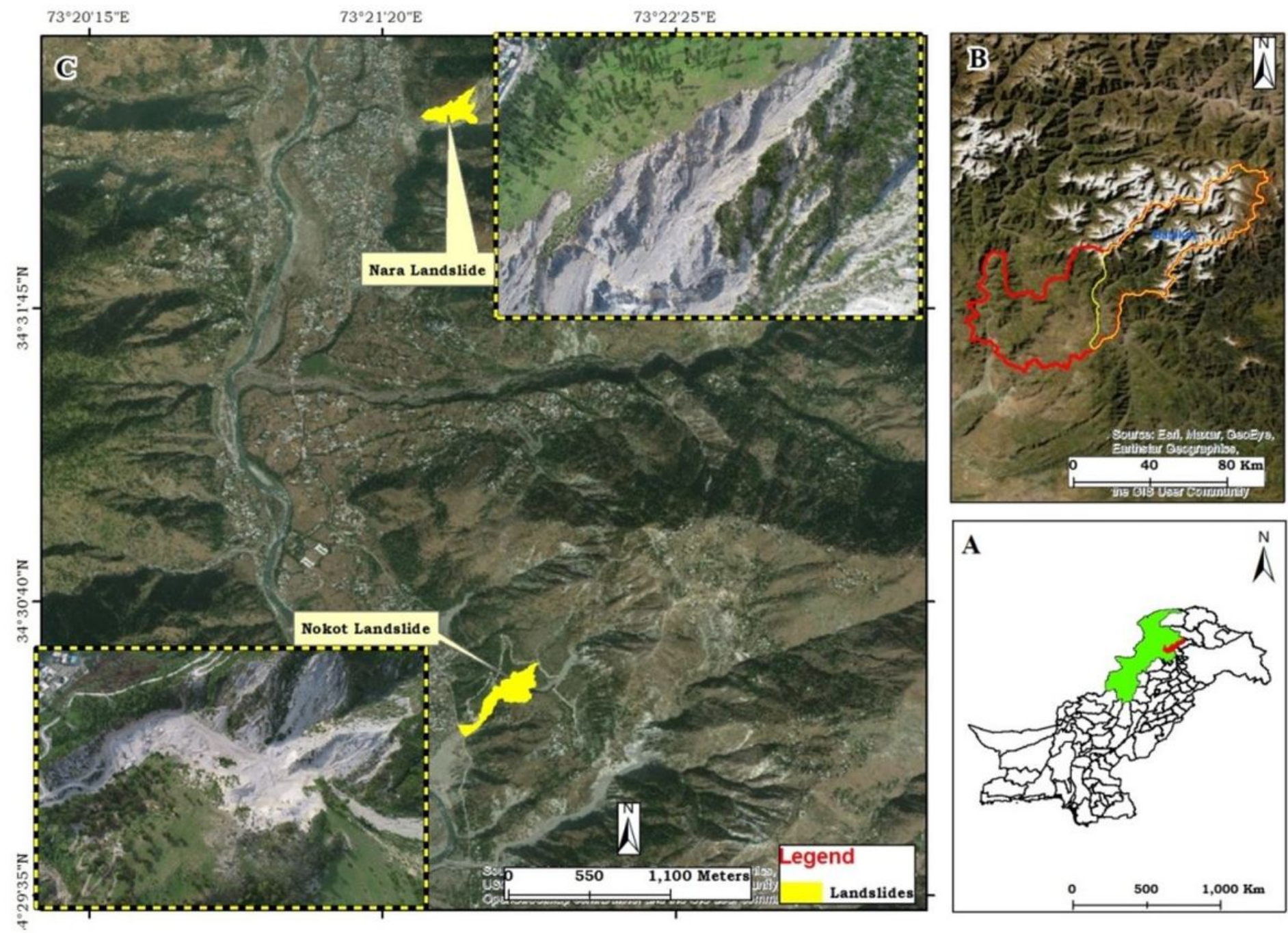

\section{Figure 1}

Location map of the study area A) Pakistan B) District Mansehra and C) The Nara and Nokot landslides. Note: The designations employed and the presentation of the material on this map do not imply the expression of any opinion whatsoever on the part of Research Square concerning the legal status of any country, territory, city or area or of its authorities, or concerning the delimitation of its frontiers or boundaries. This map has been provided by the authors. 


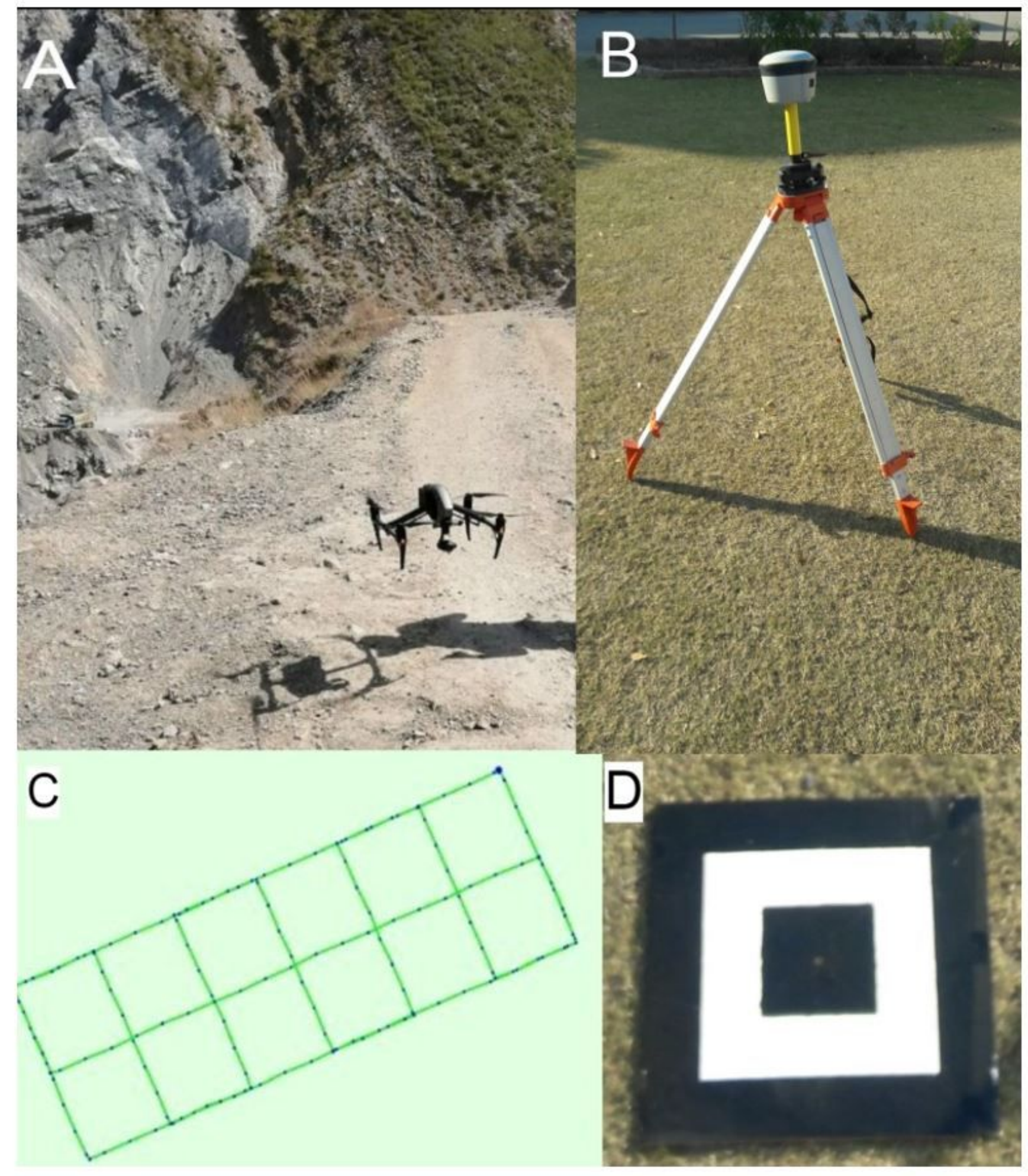

Figure 2

(A) shows DJI Inspire 2 (B) DGPS (C) Double Grid Mission.and (D) GCP 


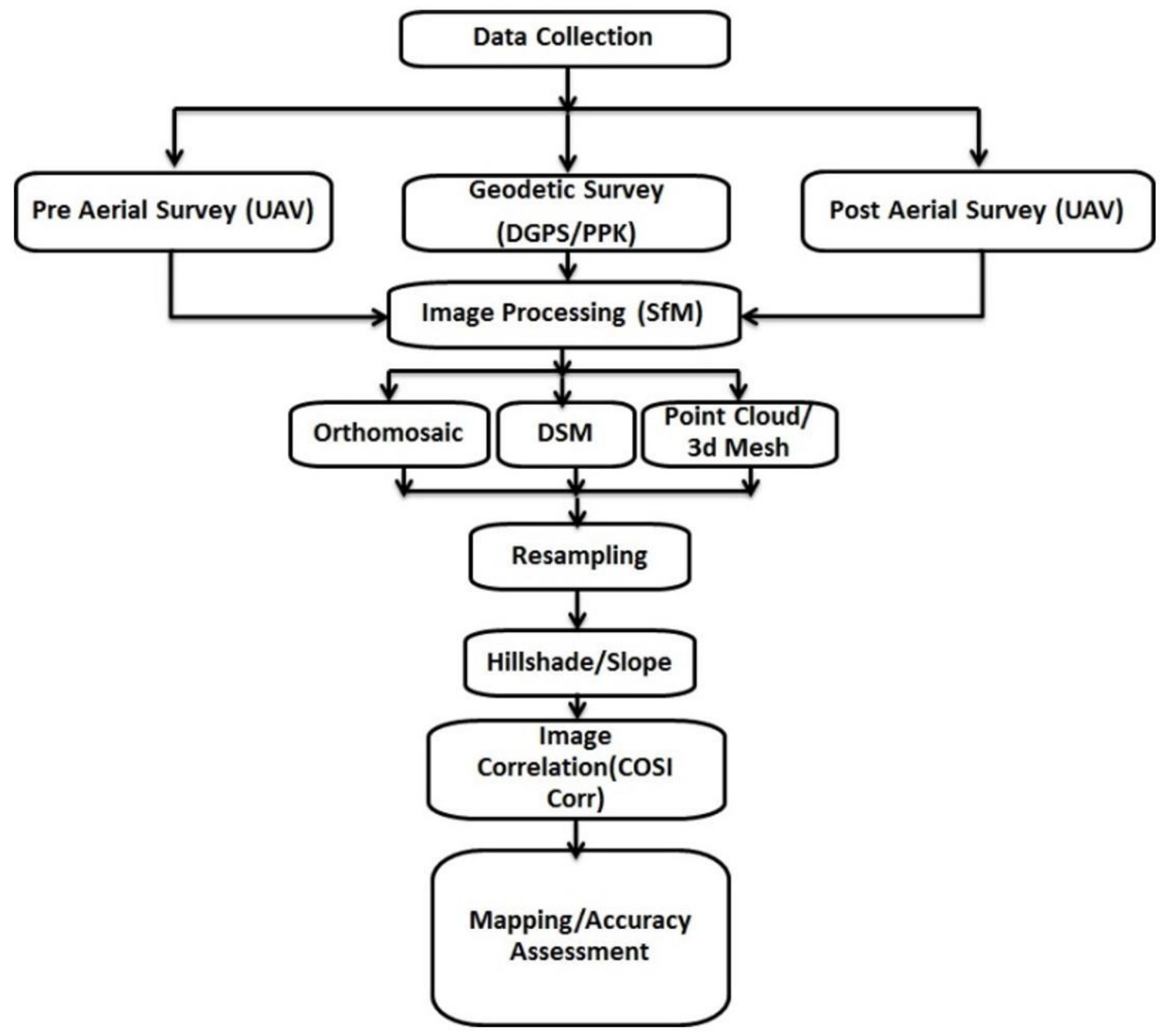

Figure 3

Flowchart of the methodology adopted for the study 


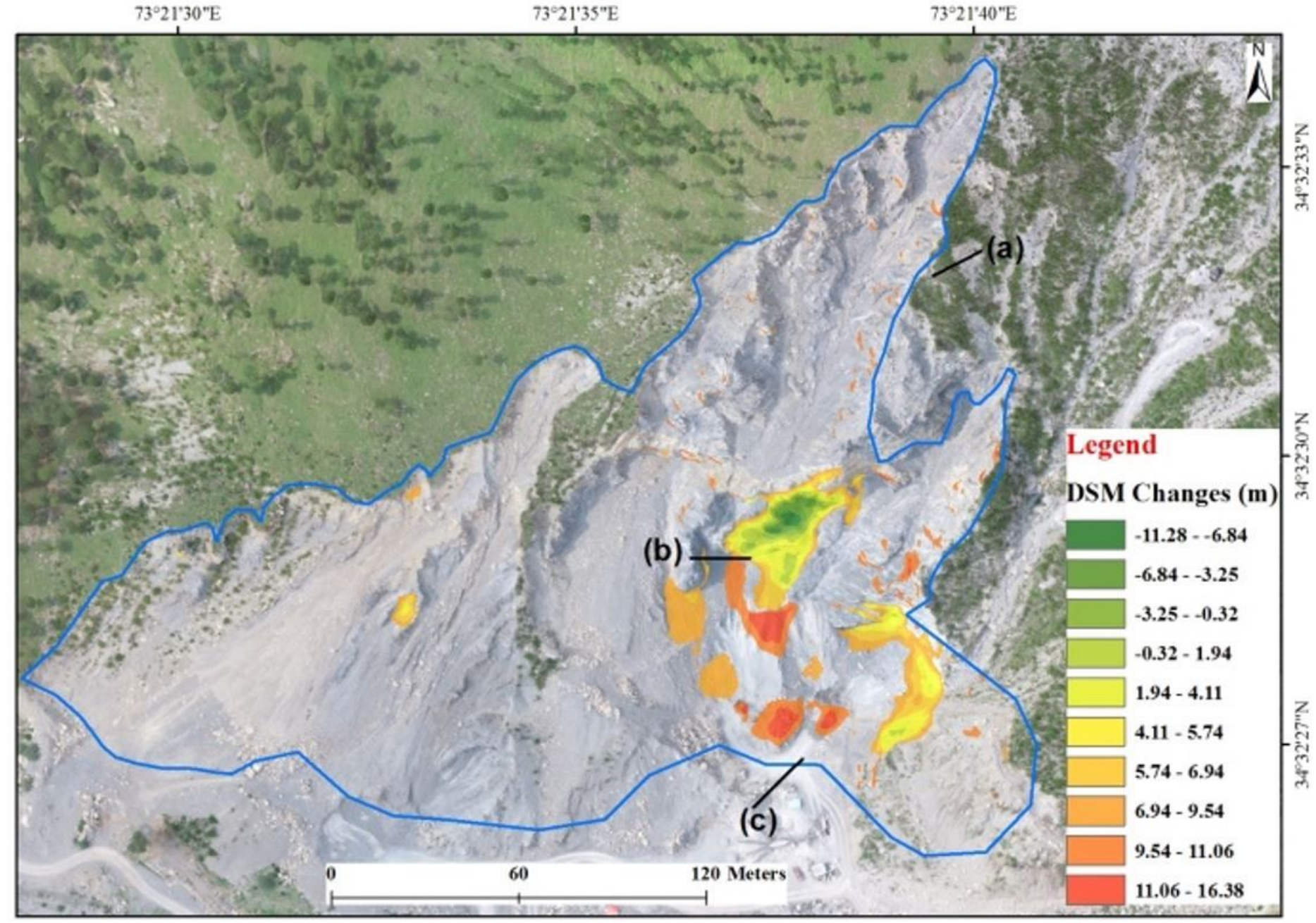

\section{Figure 4}

shows the DSM changes in the Nara landslide. Note: The designations employed and the presentation of the material on this map do not imply the expression of any opinion whatsoever on the part of Research Square concerning the legal status of any country, territory, city or area or of its authorities, or concerning the delimitation of its frontiers or boundaries. This map has been provided by the authors. 


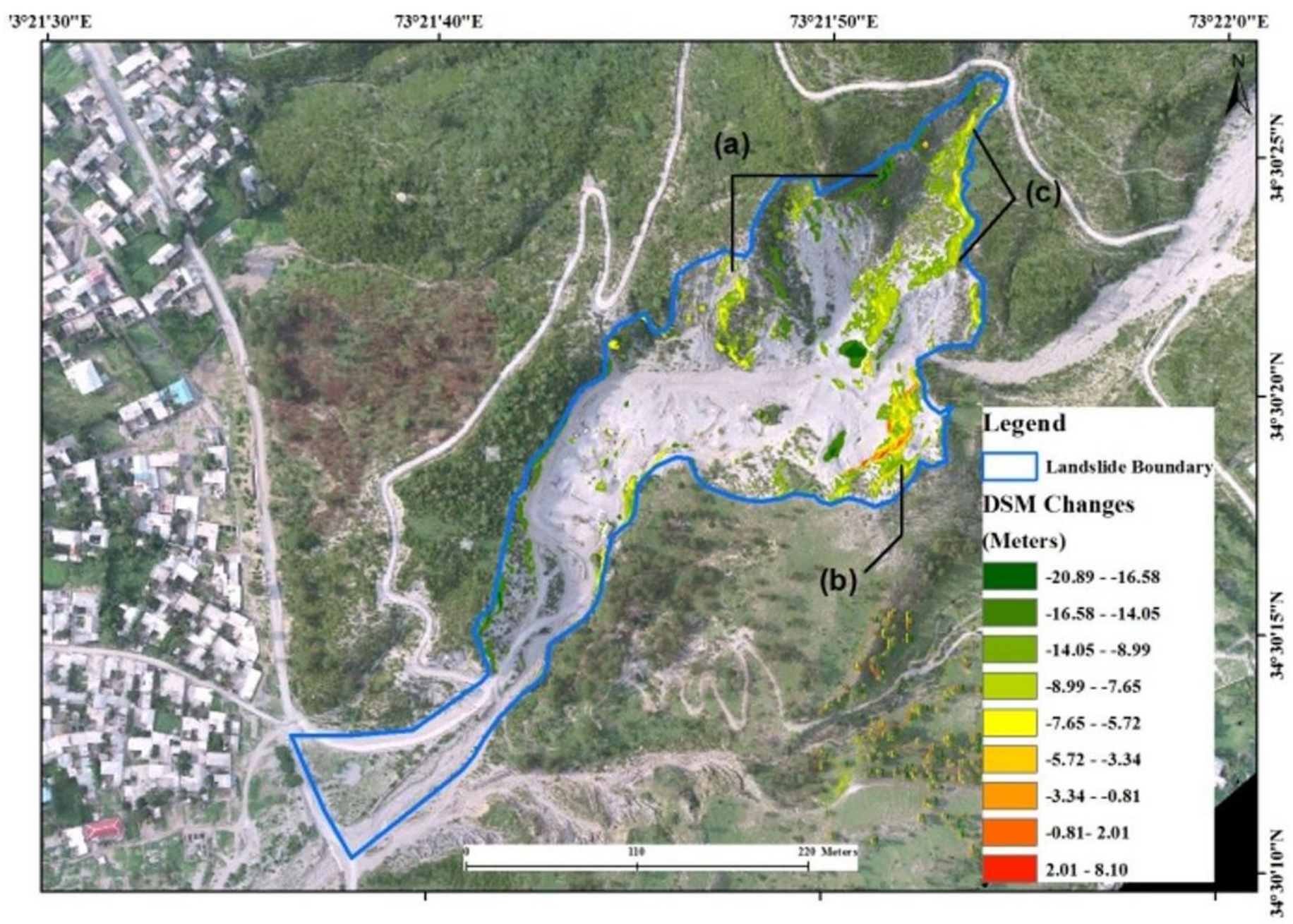

Figure 5

DSM changes in the Nokot landslide. Note: The designations employed and the presentation of the material on this map do not imply the expression of any opinion whatsoever on the part of Research Square concerning the legal status of any country, territory, city or area or of its authorities, or concerning the delimitation of its frontiers or boundaries. This map has been provided by the authors. 


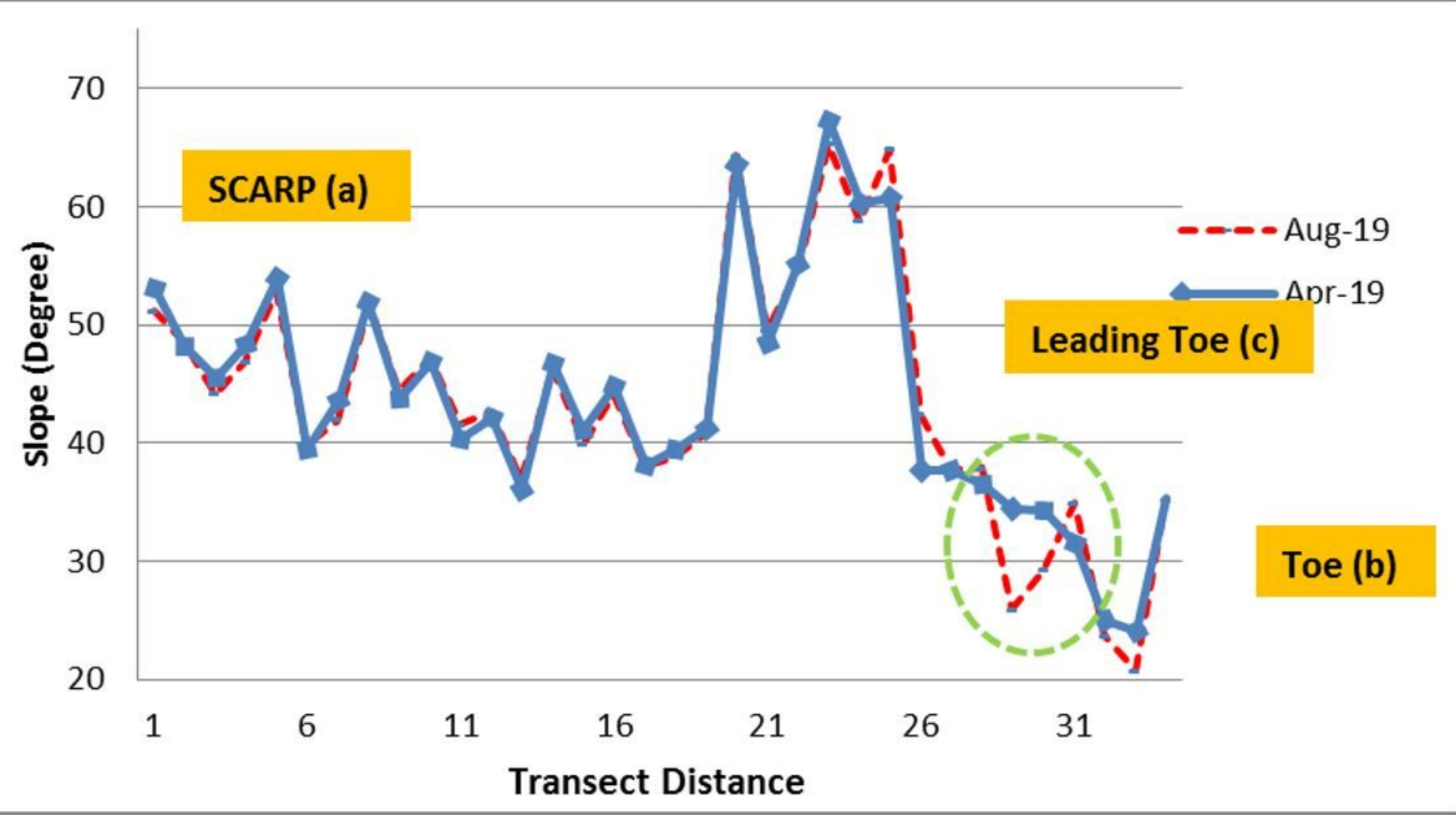

Figure 6

shows the graph describing the slope changes of the Nara landslide in April 2019 and August 2019. 


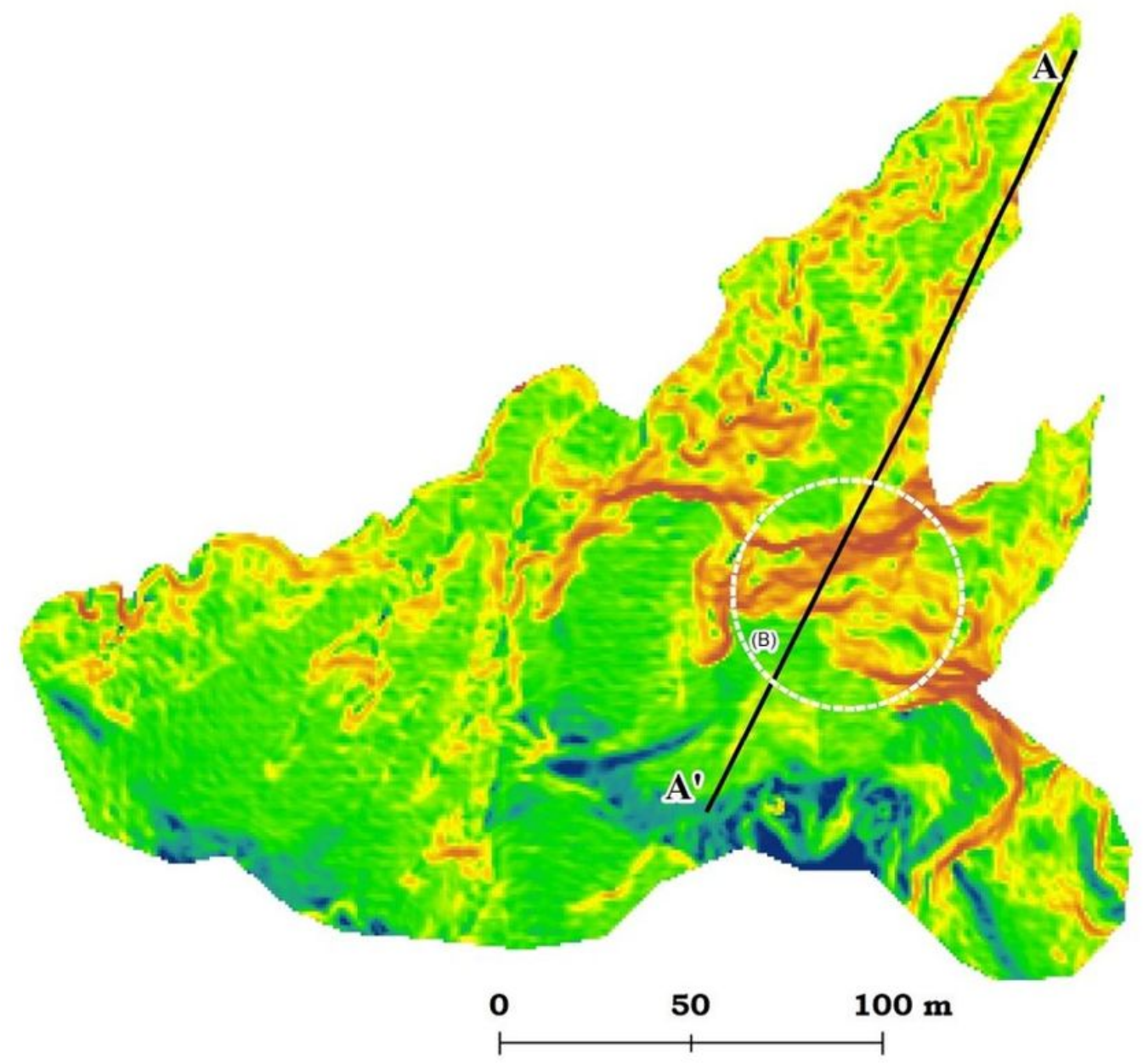

\section{Legend}

Transect Line Nara LS Slope Degree

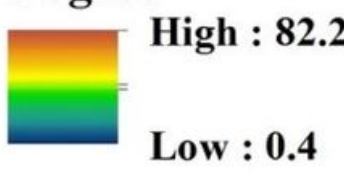

Figure 7

shows the slope and transect A-A' drawn along the Nara landslide. Note: The designations employed and the presentation of the material on this map do not imply the expression of any opinion whatsoever on the part of Research Square concerning the legal status of any country, territory, city or area or of its authorities, or concerning the delimitation of its frontiers or boundaries. This map has been provided by the authors. 


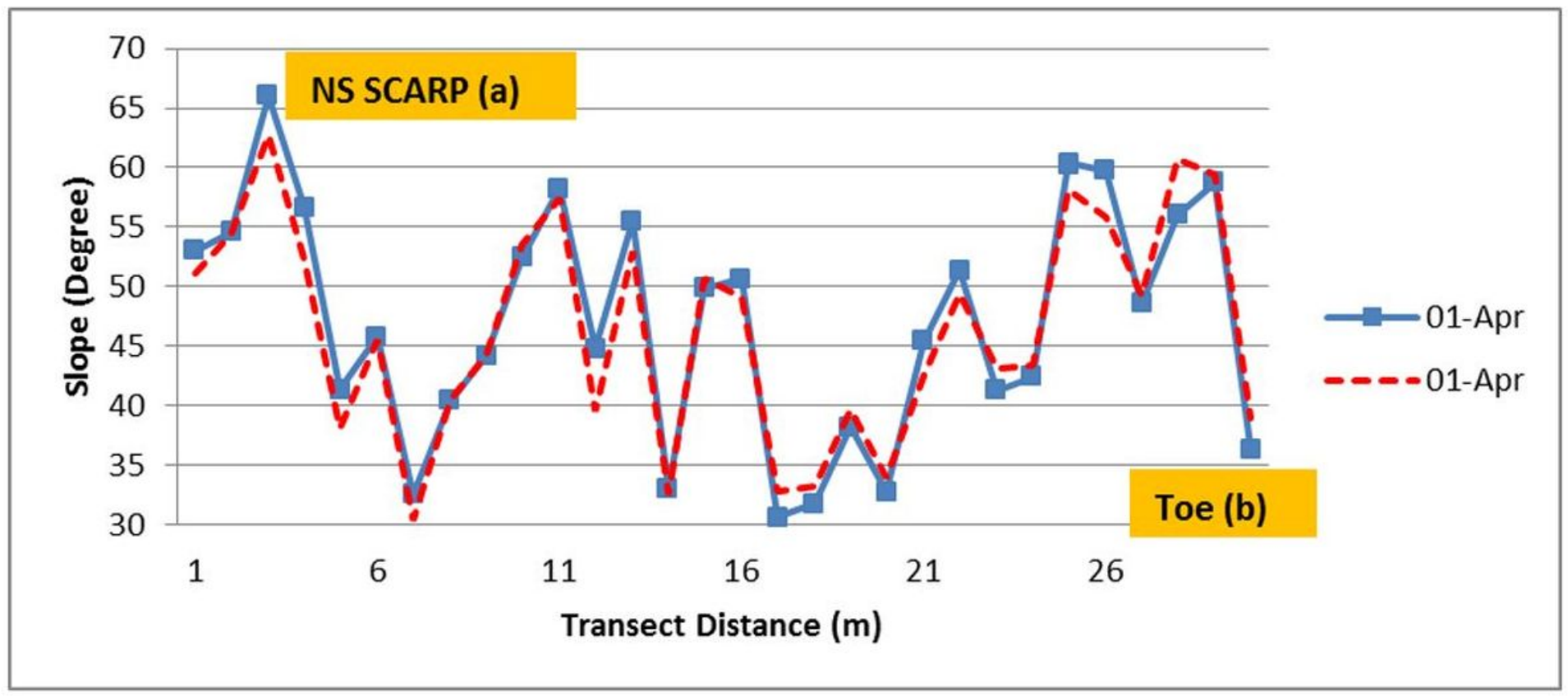

Figure 8

Shows the graph describing slope changes in the Nokot landslide 


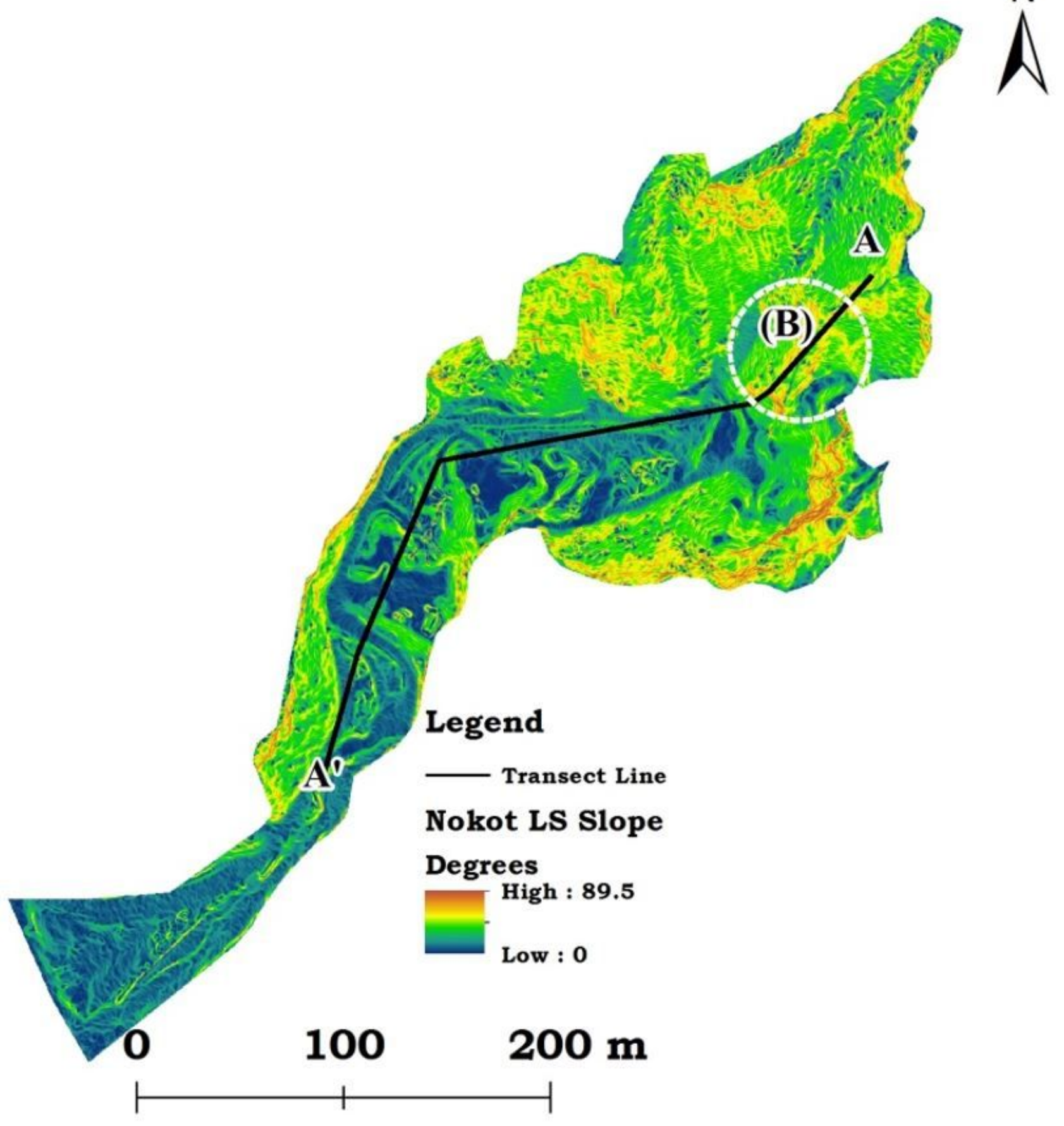

Figure 9

shows the slope along the transect line of the Nokot landslide. Note: The designations employed and the presentation of the material on this map do not imply the expression of any opinion whatsoever on the part of Research Square concerning the legal status of any country, territory, city or area or of its authorities, or concerning the delimitation of its frontiers or boundaries. This map has been provided by the authors. 


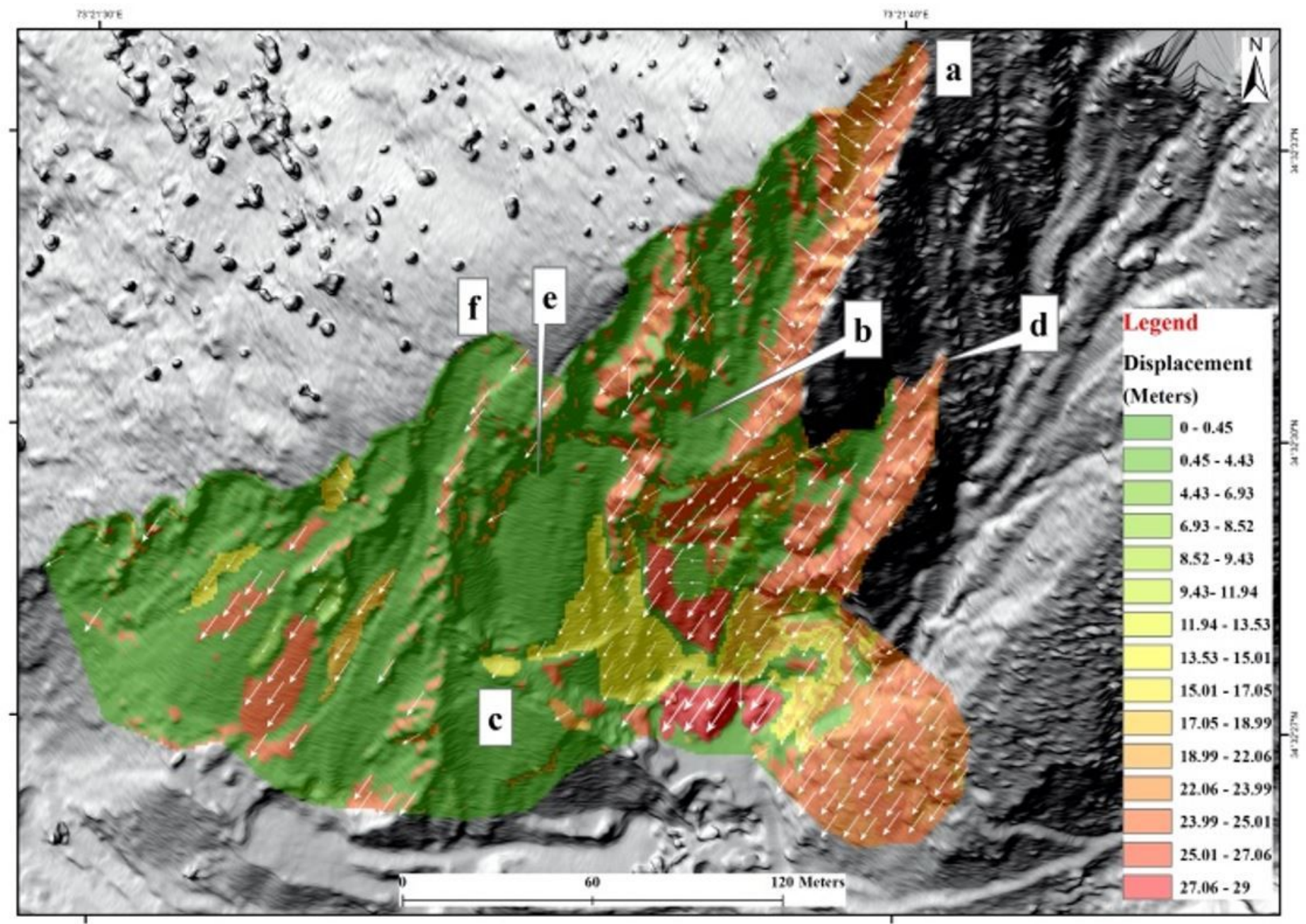

Figure 10

shows the surface movement in the Nara landslide. Note: The designations employed and the presentation of the material on this map do not imply the expression of any opinion whatsoever on the part of Research Square concerning the legal status of any country, territory, city or area or of its authorities, or concerning the delimitation of its frontiers or boundaries. This map has been provided by the authors. 


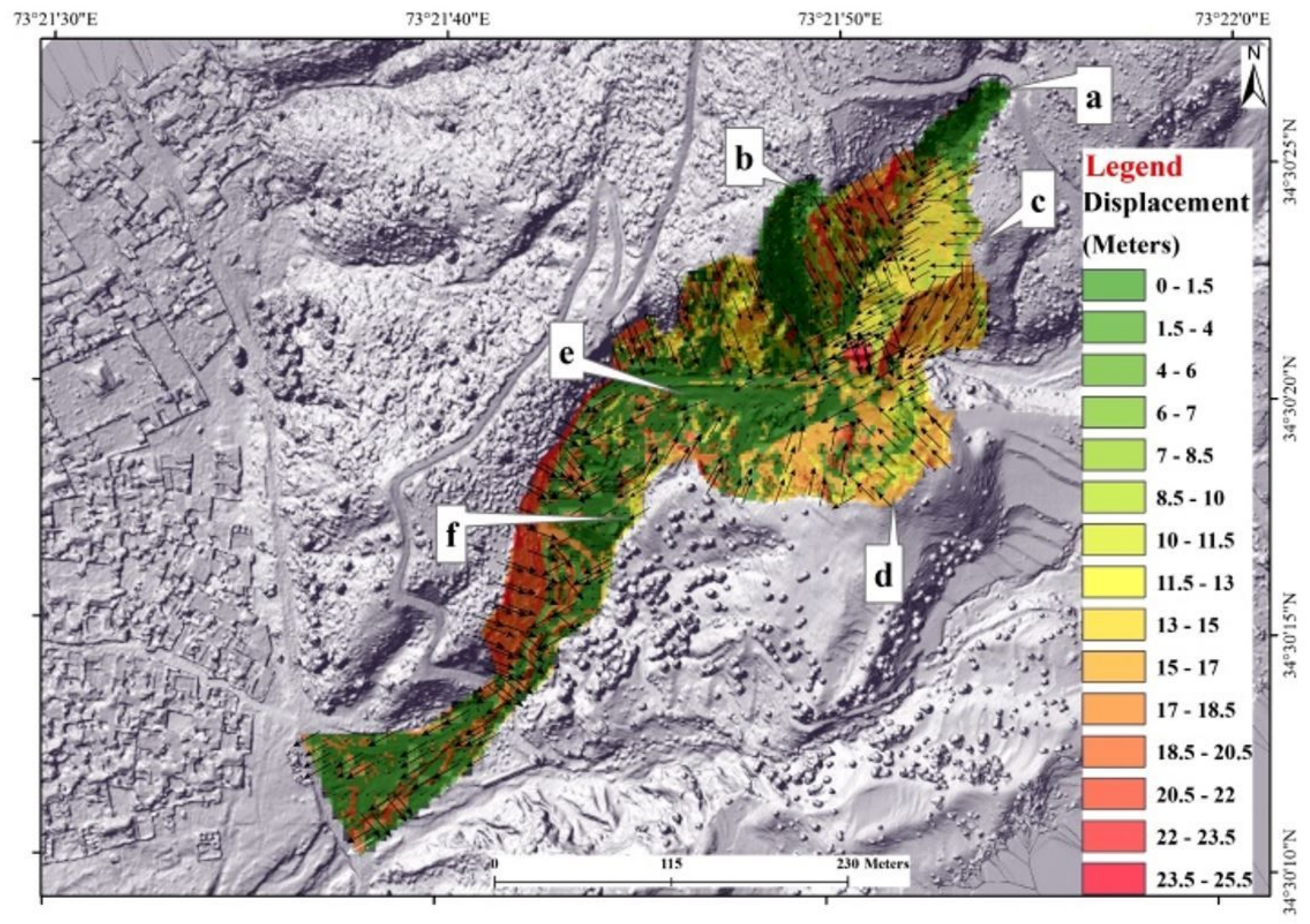

Figure 11

shows the surface movement in the Nokot landslide. Note: The designations employed and the presentation of the material on this map do not imply the expression of any opinion whatsoever on the part of Research Square concerning the legal status of any country, territory, city or area or of its authorities, or concerning the delimitation of its frontiers or boundaries. This map has been provided by the authors. 


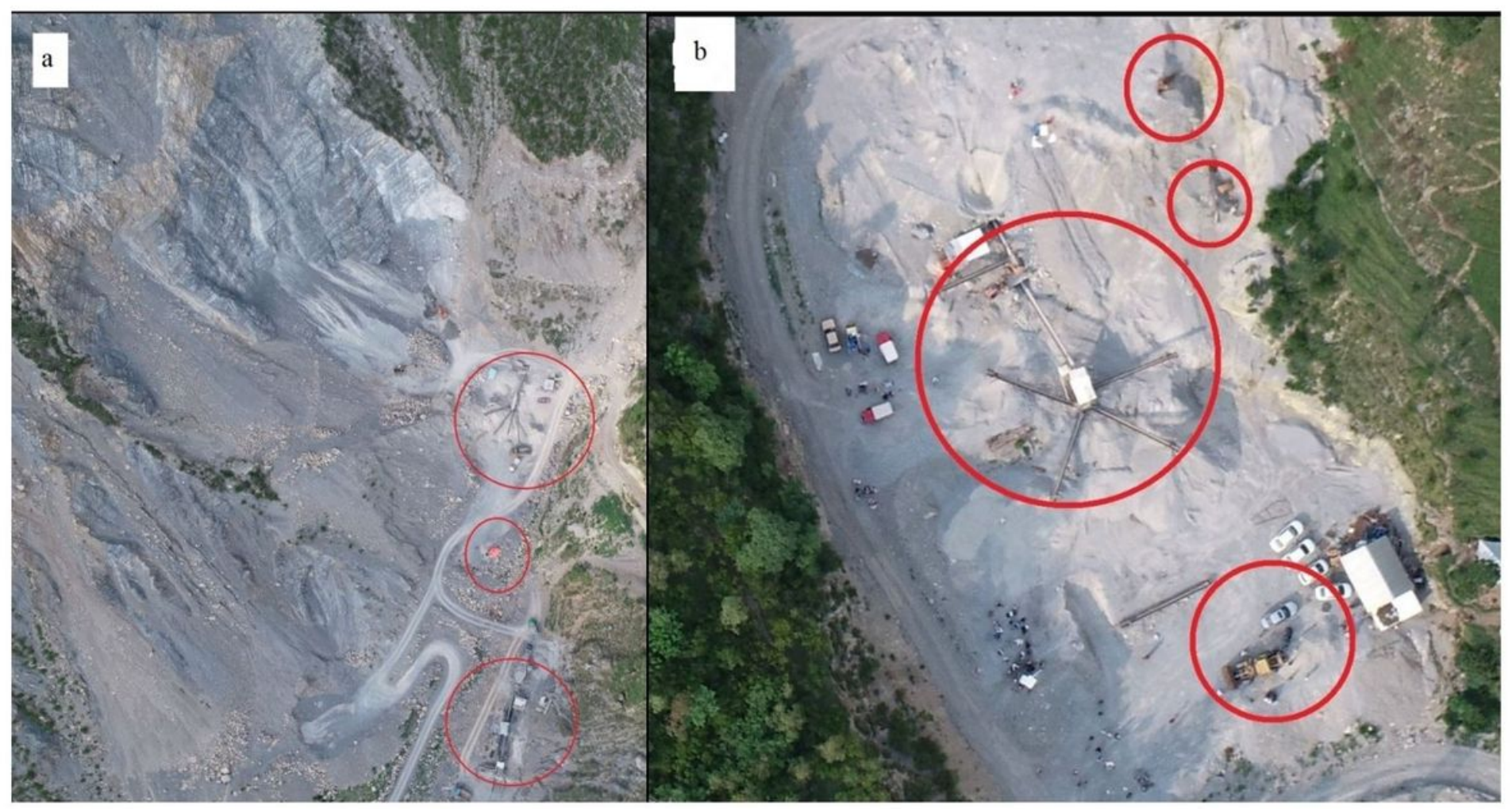

Figure 12

Shows the human-induced excavation of (a) the Nara and (b) the Nokot landslides. Note: The designations employed and the presentation of the material on this map do not imply the expression of any opinion whatsoever on the part of Research Square concerning the legal status of any country, territory, city or area or of its authorities, or concerning the delimitation of its frontiers or boundaries. This map has been provided by the authors. 